\title{
Processos de imaginação e a questão da linguagem: risços da contaminação normativa e a necessidade de preservar a essência da imagem.
}

Processes of imagination and the question of language: risks of normative

contamination and the need to preserve the essence of image

\author{
> Ana Mansur de Oliveira \\ UFRJ - PPGAV \\ Scholarship Student, nº 111003185 \\ CAPES Foundation, \\ Ministry of Education of Brazil, \\ anamansur@gmail.com
}

\author{
> Celso Pereira Guimarães, D. Sc. \\ UFRJ - PPGAV \\ Scholarship Student n 3133/13-3 \\ CAPES Foundation, \\ Ministry of Education of Brazil \\ celsopg@acd.ufrj.br
}

\begin{abstract}
This paper aims to analyse the freedom of creativity as a tool for the upcoming of new images on the contemporary scene. We investigated some values that can expand the creative gesture, considering it as an act of freedom against the risk of becoming repetitive. During this process of searching the renewal of this experience, we developed a visual project, over a theme that was kept multifaceted and fluctuant, rather than closed in a solid concept. It integrates photography, painting, typography and digital manipulation, and was the result of a poetic dive that is discussed along this article.
\end{abstract}

Keywords: art, imagination, language

\section{Introdução}

Essa pesquisa investiga o processo de realização de um projeto artístico e de seu respectivo lugar poético, apresentando os movimentos teóricos entrelaçados às etapas de confecção de imagens. Para tanto, trabalhamos com a visão de Benjamin (1987), para quem é fundamental considerar que a linguagem não pode estar restrita ao mero estabelecimento de semelhanças percebidas pela dimensão sensível do homem. Ao contrário, é preciso considerá-la como mediadora entre o pensamento humano e os fenômenos, e nunca restritiva ao ponto de reduzir as particularidades daquilo que busca representar. A linguagem, para ele, é mais "coisa” do que "meio". Existindo em si, parte do princípio que existe um apelo inerente ao objeto para que se realize então a nomeação. Dessa forma, a essência linguística se colocaria necessariamente atrelada à essência espiritual.

A linguagem normativa é considerada prejudicial por Benjamin, pois traz o risco de extrair apenas a "média" daquilo que busca representar, excluindo grande parte de uma dimensáo que poderia ser denominada mágica. Nesse caso, ela deixaria de se colocar como parte de uma força criadora para assumir um lugar meramente instrumental. A compreensão do fazer artístico contemporâneo se beneficia dessa visão que o autor ilumina em sua concepção de linguagem: ela não apaga o particular, pois trabalha na direção de buscar recolher os extremos das coisas. Deixa de ser meio para se constituir como ação.
A visão de Benjamin acerca da compreensão da arte busca "recompor suas ruínas e ressuscitar seus mortos" ${ }^{\text {. Para Rouanet }}{ }^{2}$ trata-se de um desejo de redençáo das coisas. É de um risco de contaminação normativa que se pretende proteger o objeto, buscando investigar não a linguagem instrumental, mas aquela que se desprende espontaneamente do referente. Para isso, é necessário aceitar características como a descontinuidade e a justaposição, nesse método que procura pela compreensão dos fenômenos da arte. Nesse caso, não se está buscando uma unidade objetiva, mas uma imersão que pode ser constantemente renovada ${ }^{3}$. Ao descrever o mundo das idéias sem buscar apropriar-se delas, a conceituaçáo serviria aqui a um fim diferente daquele que busca dominar ${ }^{4}$ as coisas. Ao contrário: nesse processo, o movimento é redimi-las para que sua essência se mantenha protegida.

Nesse ponto nos parece oportuno conjugar a visão de Deleuze \& Guattari (1997), sobre o conceito: para os autores, ele seria uma simples mediação entre o particular e o universal, executando o que seria uma mera aproximação entre os dois. A idéia, ao contrário, se propóe a preservar a singularidade, incorporando maior diversidade.

$\begin{array}{ll}1 & \text { Benjamin, 1984:46 } \\ 2 & \text { in Benjamin (1987:15) } \\ 3 & \text { Benjamin, 1984:22 } \\ 4 & \text { Benjamin, 1984:22 }\end{array}$


Essa distinção nos ajuda a compreender o método de Benjamin na pesquisa estrutural da análise da obra de arte. Em "A origem do Drama Barroco Alemão", o autor exerce um procedimento dissociativo, perpassando os extremos para alcançar finalmente a essência da obra que procura investigar. Porém, pontua o lugar ocupado pela idéia em oposição ao conceito: ela é o equivalente à própria linguagem.

A contemplação da "idéia" ocorre como se ela fosse "coisa", preservando o particular dos fenômenos. Para essa pesquisa, que busca investigar práticas artísticas contemporâneas, o método de Benjamin pode ser considerado profundamente atual. O procedimento do autor perfaz um mergulho no objeto até que, enfim, em sua estrutura, se revele sua própria origem. Dessa forma, através do exame dos particulares, aparecem então as leis do todo, e esse processo é deflagrado pelo próprio objeto, e não pelo desejo do observador de investigá-lo. Dessa forma, não há separação possível entre o objeto e sua respectiva análise.

Para Rivera (2013) não é possível comunicar a essência do sujeito, e sim transmiti-la, como em uma missáo ${ }^{5}$. Esse seria um papel tornado possível pela arte. Considerando, por exemplo, o lugar da falta como inerente ao sujeito, o artista recolheria os restos desse desejo, revestindo-o daquela tonalidade sensível inerente ao objeto de arte. Uma questão que interessa nossa pesquisa é a potência da obra em carregar sua própria crítica, ao invés de demandar pelo olhar do investigador. Rivera aponta para o pensamento crítico que, ao invés de diagnosticar, passa adiante "a crise que é o próprio trabalho artístico"6.

Podemos aqui traçar um paralelo entre a torção da linguagem que Deleuze identifica quando um objeto se constitui arte. A vibração e a ruptura que o artista realiza na linguagem arranca o percepto e o afecto que tornam a obra viva e pulsante, conservando sua aura sensível para o futuro. ${ }^{7}$ Para o autor, essa extração corresponde a tornar visíveis sensaçóes ocultas que já povoam o mundo. $\mathrm{O}$ fazer artístico, dessa forma, se coloca como composição. E só progride, caso sejam içados desse oceano novos afectos e perceptos. Esse movimento acontece através do trabalho do artista com a torção da linguagem: desviando, mudando de nível, ou alterando escalas, enquadra entáo o real com a luz diferenciada que o transforma em arte.

\section{Metodologia}

Essa pesquisa desenvolve-se no sentido de cercear determinado local imaginal sem, no entanto, pretender dominá-lo inteiramente, evitando o risco de contaminação através de uma normatização excessiva. Através de uma revisão bibliográfica e da produção de textos que antecedem à confecção de imagens, trabalhamos uma aproximaçáo com nosso objeto imagético sem que isso signifique apropriar-se completamente dele.

A pesquisa iniciou-se com uma inquietação a partir da observação de uma busca que, em nosso habitar poético, se relaciona

$\begin{array}{ll}5 & \text { Rivera, 2013:187 } \\ 6 & \text { Rivera, 2013:197 } \\ 7 & \text { Deleuze \& Guattari, 1997:228 }\end{array}$

com o desejo humano de completude. Ao mesmo tempo em que as cercanias desse lugar imaginal eram construídas, desenrolou-se a pesquisa de imagens. Em um primeiro momento, o suporte ideal foi a fotografia, e o pretexto que mais trazia questóes era o brinquedo infantil. Ao entrar em contato com os resultados dessa primeira fase da pesquisa, percebemos que as imagens produzidas, de alguma forma, buscavam profanar esses objetos, ávidos por representar a perfeição. No entanto, a manipulação sobre os originais passou a se constituir uma necessidade poética, na medida em que se ampliava a compreensão desse lugar imaginal. O processo aconteceu simultaneamente, ou seja, leituras e indagaçôes entremeavam-se com a própria produçấo de imagens. $\mathrm{O}$ resultado da primeira fase desse projeto (figura 1), foram interferências de vários tipos sobre as fotografias, como a manipulação digital, que aplica filtros, ajustes de cores e alteraçóes de luz, além de sobreposiçóes de desenhos feitos em nanquim e digitalizados para uma posterior composição sobre as imagens originais.

A busca no sentido de desconstruir esse desejo de perfeição simbólica desenvolveu-se em paralelo com o desafio de que a composiçấo final permanecesse abastecida por uma carga ideal de alegria, ainda que atestando essa eterna incompletude. $\mathrm{O}$ mosaico que surgiu depois, com as áreas em negro (figura 2), procurava dar conta de uma espécie de manto ideal, aquele que, em sonho, busca cobrir todos os aspectos da vida, sem nunca esgarçar-se. $\mathrm{O}$ impulso de compor um conjunto, ao invés de expor as imagens em separado, relaciona-se com um desejo impossível de controlar esse todo. Ao mostrar-se irrealizável, admite-se então a saída possível: desconstruí-lo. A vontade oculta de um aquecimento eterno da alma, precisava ser ironizada, talvez profanada, de acordo com nosso lugar poético. Dessa forma, as áreas vazias, de certa forma,

Figura 1: Fase inicial da pesquisa: fotografias de brinquedos, com desenhos e manipulação digital, ainda sem constituirem-se um mosaico.

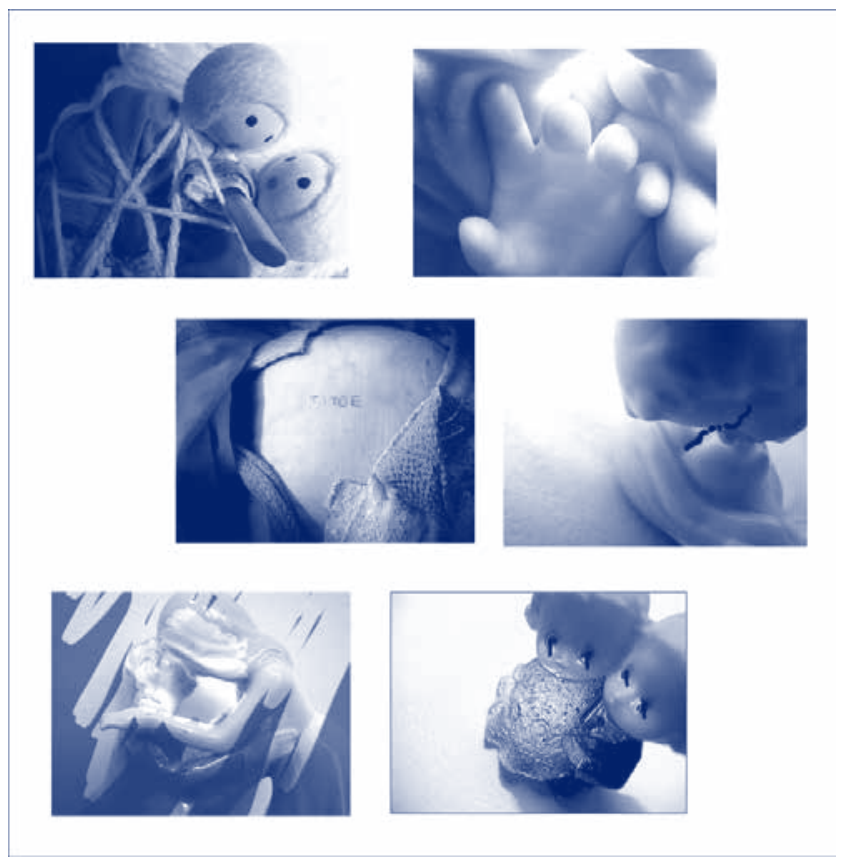


podem trazer a existência das falhas, das quebras, das interrupçóes inerentes à própria condição humana.

Ao procurar compreender parte dos limites da vida, particularmente aqueles trazidos pelos desígnios do Tempo, seguimos com a pergunta trazida por Paz (1974): "não há um jeito de sair do círculo do tempo? . Ao investigar a maneira como a era moderna constrói sua relaçáo com o Tempo, deduz que, para nós, "a perfeição não

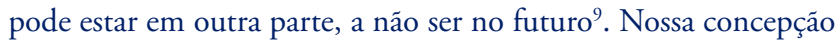
de Tempo o coloca como agente do inesperado, e o possível "vir a ser" do futuro se reveste de um brilho sempre novo, que seduz pelo simples fato de ainda não existir. Durante a pesquisa, os movimentos de construção da imagem foram embalados por um desejo de anular essa entidade imperfeita: o Tempo e suas contínuas mudanças. Essa divisão infinita de tudo nos afasta do ideal de perfeição, em que reinaria o todo, a Unidade. Para esse estudo, esse foi mais um encontro importante tanto na teoria quanto na prática, na medida em que foi possível realizar um relato de criação em que entrelaçam-se indefinidamente idéia e projeto.

Diante disso, longe de construirmos uma atmosfera de resignação, o impulso projetual buscado incorporaria a alegria como afeto básico. O diálogo que Macedo (2008) estabelece entre Freud e Spinoza nos ensina que o Tempo é fundamental para a construção dessa nova Alegria. Tanto para Freud quanto para Spinoza, essa alegria deriva do trabalho de pensamento, o que afirma a soberania de uma certa paciência elástica, ao contrário de uma perfeição imediatista, mas desintegradora. Para o filósofo, nossas paixóes "não se explicam por nossa essência ou potência, mas pela potência de uma coisa exterior; assim, elas envolvem nossa impotência. Toda paixão nos separa de nossa potência de agir; enquanto nosso poder de ser afetado for preenchido por paixôes, estaremos separados daquilo que podemos". ${ }^{10}$ Dessa maneira, conseguimos perceber que, para Spinoza, nenhuma serventia há na tristeza, na medida em que ela simplesmente diminui nossa potência de agir. Como sintetiza Machado: "não pode haver tristeza ativa ou ação triste"11. É o ser em sua plena posse de agir. Essa é a imagem que nos interessa, pois coincide com o ser Real, aquele que, apesar de conhecer os limites e reconhecer-se falho, encontra-se na alegria da produção de açóes, em constante movimento.

Durante o desenvolvimento dessa pesquisa imagética, determinadas leituras conquistaram um lugar estratégico na construção desse espaço imaginal. Com a maior participação do texto, a palavra passou a reverberar internamente, de certa forma clamando por espaço ao lado das imagens. No movimento de aproximaçáa com esse lugar poético, algumas frases passaram a sobressair em nosso imaginário artístico, pulsando por um espaço mais ativo na composição, complementar ao trabalho com as fotos (figura 3). Porém, a carga dessas construçóes verbais necessitava de um tratamento orgânico, pulsante como seu conteúdo. Pintá-las com tinta

\footnotetext{
$8 \quad$ Paz, 1974:29

9 Paz, 1974:28

10 Spinoza apud Machado, 2010:78-79

11 Machado, 2010:81
}

para em seguida submetê-las à manipulação digital trouxe uma via de saída para o enigma imagético que se desenrolava.

A leitura de textos relativos à psicanálise nos levou a Maurano (2003), que escreve sobre a "pressão do não-ser"12. A princípio, esse lugar inconsciente traz em sua raiz o trauma, ao incluir a morte e outros limites. Porém, essa energia de se assumir a incompletude pode ser revertida também em ação - impulsionada pelo alegria assim como estuda Spinoza. Para a psicanalista, há um deslocamento

\section{Maurano, 2006: 44}

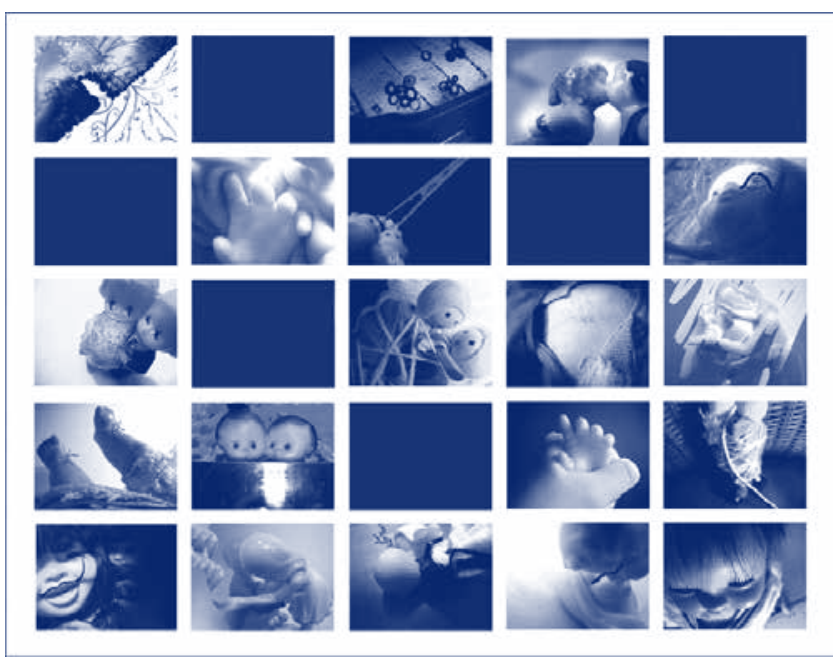

Figura 2: Primeira composição das fotografias intercaladas com áreas negras, ainda construindo-se como um conjunto controlado.

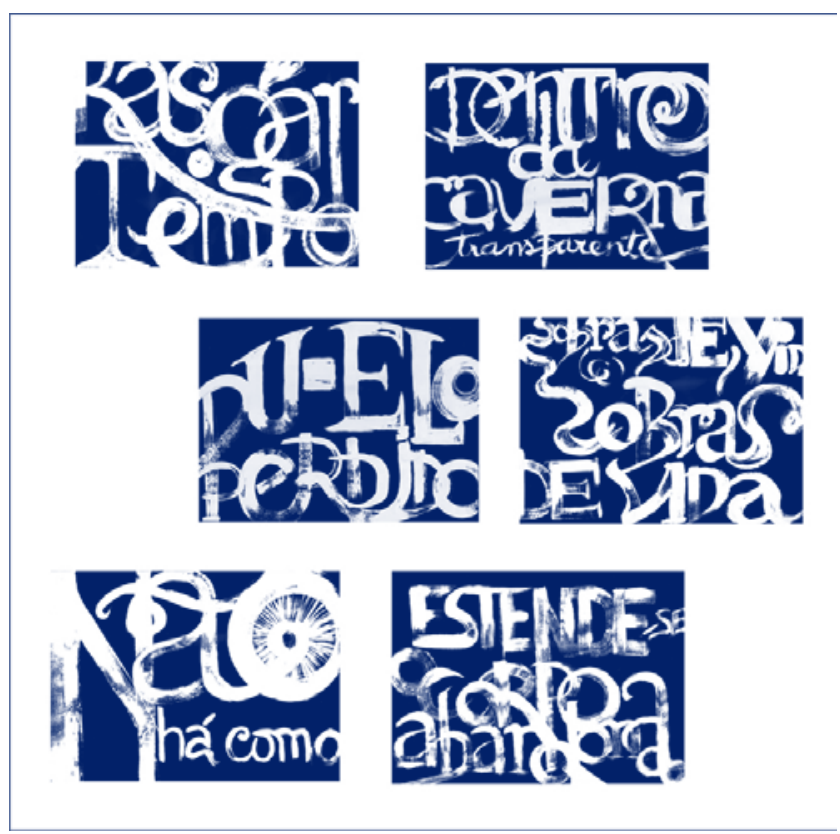

Figura $\exists$ : Experiências com pinturas e posterior manipulação digital de frases significativas ao propósito poético. 


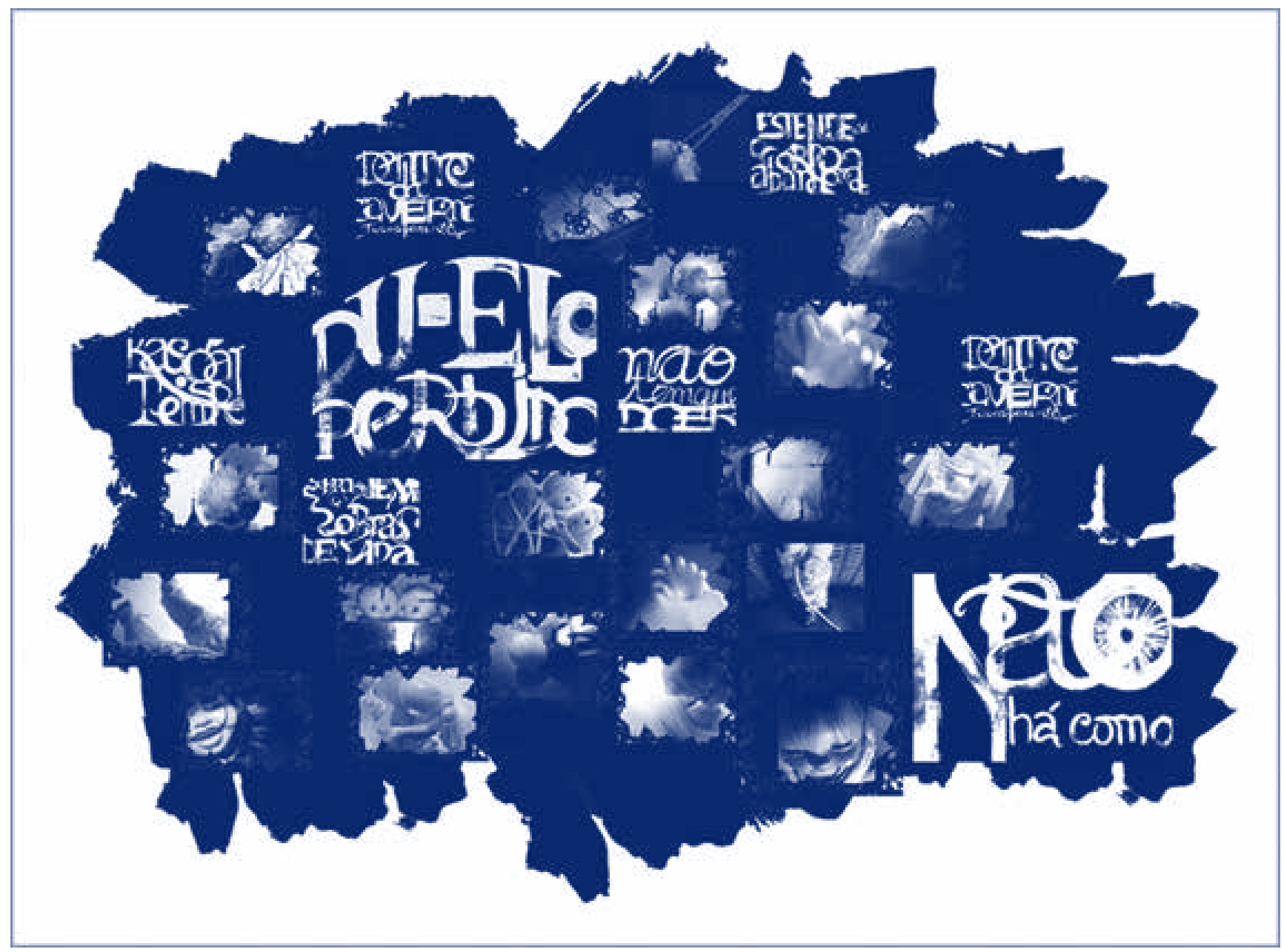

Figura 4: Fase final da pesquisa: painel constituído pelo mosaico de fotografias, desenhos e textos, com manipulação digital, com uma integração mais pulsante das imagens.

do sujeito que, através da análise, mantém-se gravitando em torno do amor, mas passa de passivo a ativo. Dessa forma, ao invés de demandar repetidamente ser amado, desse novo lugar em que se reconhece a dimensão do inconsciente, ele tem então a coragem de afirmar sua ação de amar. O ser acolhe então esse vazio, reconhecendo que, apesar de seu preenchimento ser impossível, aceitá-lo possibilita que algo seja feito a partir desse encontro.

O percurso que nos trouxe até esse resultado, foi vasto e inconstante, porém descortinou um centro sensível que irradia uma relação a partir desse encontro com o vazio. A produçáo de imagens dialoga com esse desejo irrealizável da confecçáo desse manto perfeito que cobriria os vários aspectos da existência. $\mathrm{Na}$ fase seguinte de desenvolvimento da pesquisa, o mosaico encontrava-se ainda rigidamente organizado (figura 2), tamanha sua dificuldade em não esgarçar-se, em sua ambição de controle.

O trabalho final (figura 4), ainda aberto a novas incursões, é uma composição mais explosiva, em que os fragmentos de sensação representados pelas imagens, desenhos e textos coexistem, ora salpicados com a energia do movimento, ora atestando o temor da falta. No entanto, assume a impossibilidade de se confeccionar uma cobertura organizada para nossa concepção da existência. Falhas, saltos, ordem, desordem, ironia e até conformaçáo buscam espaço em um mosaico que quer celebrar o imperfeito, afirmando-se como instável e pulsante.

Resultados esperados e possiveis debates

Nossa pesquisa e laboratório de criação tem como objetivo encontrarse com o mundo, buscando estabelecer uma relação intersubjetiva com a audiência, para que as experiências visuais motivem atitudes transformadoras por parte daquele que as vê. Acreditamos que a partir desse encontro com obra, o receptor possa integrar-se ao habitar poético iluminado pelo artista-pesquisador, compartilhando da aura sensível do próprio processo até a imagem final.

A imaginação é uma forma de apreensão e recriação da realidade, que impulsiona o pensamento na direçấo de potencializar a capacidade de criação de onde emerge a imagem "nova". Algumas questôes podem surgir para debate a partir desse estudo, como: quais os significados das experiências imagéticas? Como ativar o potencial imaginativo dos criadores de experiências da imagem com significado $^{13}$, assumindo que tanto o processo da imaginação como 
os significados levantados pelo encontro com a arte são múltiplos e orgânicos? Esperamos ter oferecido material para reflexão para evitar que essa experiência torne-se repetitiva, e o canal de criação possa permanecer flutuante, ainda que circunscrito.

\section{Agradecimentos}

Gostaríamos de agradecer ao PPGAV - Programa de Pós-Graduação em Artes Visuais da UFRJ e à CAPES, Coordenação de Aperfeiçoamento de Pessoal de Nível Superior, cujo apoio foi fundamental para o desenvolvimento dessa pesquisa.

\section{Bibliografia}

AGAMBEM, Giorgio (2007). Profanaçôes. São Paulo: Boitempo BENJAMIN, Walter (1987). Magia e técnica, arte e política. Ensaios sobre literatura e história da cultura. Obras Escolhidas v.1. São Paulo: Brasiliense

DELEUZE \& GUATTARI (1997). O que é a Filosofia? São Paulo: 34

CAUQUELIN, Anne (2005). Arte Contemporânea: uma introdução. São Paulo: Martins Fontes

CAUQUELIN, Anne (2005). Teorias da Arte. São Paulo: Martins Fontes
FLUSSER, VILÉM (2008). O Universo das Imagens Técnicas: elogio da superficialidade. São Paulo: Annablume

MACEDO, Heitor O’Dwyer de Macedo (2008). Cartas a uma Jovem Psicanalista. São Paulo: Perspectiva

MACHADO, Roberto (2009). Deleuze, a arte e a filosofia. Rio de Janeiro: Zahar

MAURANO, Denise (2006). A Transferência. Rio de Janeiro: Jorge Zahar

MAURANO, Denise (2003). Para que serve a psicanálise. Rio de Janeiro: Jorge Zahar

NASIO, J. D. (1997). Liçóes sobre os sete conceitos cruciais da psicanálise. Rio de Janeiro: Jorge Zahar

NUNES, Benedito (2007). Hermenêutica e Poesia. Belo Horizonte: Editora UFMG

PAZ, Otavio (1974). Os Filhos do Barro. Do romantismo à vanguarda. Rio de Janeiro: Nova Fronteira

SHEDROFF, Nathan (2009). Information Design 1.1. Experience Design Books

RIVERA, Tânia (2013). Arte contemporânea e psicanálise. São Paulo: Cosac \& Naif 